\title{
Determination of Atmospheric PAHs Concentration by Using Honeybee and Passive Air Sampler
}

\author{
Emine Gurkan Ayyildiz ${ }^{1}$, Mehmet Ferhat Sari ${ }^{1}$, Mesut Ertan Gunes ${ }^{2}$, Yucel Tasdemir ${ }^{1}$, Fatma Esen ${ }^{1}$ \\ ${ }^{1}$ Department of Environmental Engineering, Faculty of Engineering, Uludag University \\ Nilufer/Bursa, Turkey \\ eminegurkan@hotmail.com; $031250041 @$ ogr.uludag.edu.tr; tasdemir@uludag.edu.tr; payan@uludag.edu.tr \\ ${ }^{2}$ Department of Food Technology, Vocational School of Technical Sciences, Uludag University \\ Nilufer/Bursa, Turkey \\ egunes@uludag.edu.tr
}

\begin{abstract}
Air pollution is one of the factors that has a significant impact on human health, especially in many developing countries. In this study, polycyclic aromatic hydrocarbon (PAH) levels and cancer risk caused by inhalation were determined in an urban (Ovaakca) and a semi-urban (Cumalikizik) sites in Bursa, Turkey's 4th largest city. In this context, this research was carried out between May 2017 - September 2017 (beekeeping period), with passive air sampling and honeybee media. Sampling was carried out in two weeks intervals during the beekeeping period. The mean $\sum_{14} \mathrm{PAH}$ concentration values, obtained by polyurethane foam (PUF) disk media during the sampling period, was $198.62 \pm 24.93 \mathrm{ng} \mathrm{m}^{-3}$ in the Ovaakca site, while in the Cumalikizik site was $445.47 \pm 59.21 \mathrm{ng} \mathrm{m}^{-3}$. The lowest PAH concentration in PUF disc media was measured in Ovaakca region, and the highest concentration was measured in Cumalikizik region in June. Similarly, the total $\sum_{13} \mathrm{PAH}$ concentration obtained in the honeybee media during the sampling period was $380.87 \pm$ $115.33 \mathrm{ng} \mathrm{g}^{-1} \mathrm{dw}$ for the Ovaakca sampling site, and $217.96 \pm 30.10 \mathrm{ng} \mathrm{g}^{-1} \mathrm{dw}$ for the Cumalikizik sampling site. The highest concentration level in the honey bee media in the Ovaakca region and the lowest concentration level in Cumalikizik site were measured in September. Inhalation cancer risk was determined for adults (70 years) using PUF disc media concentration values. It is seen that the Cumalikizik site located next to the picnic area had a higher risk of cancer. Both compounds, Benzo[a]pyrene (BaP) and Benzo[a]anthracene (BaA) are the most common species used to determine cancer risk.
\end{abstract}

Keywords: Air pollution, PAHs, passive air sampling, bee, cancer potential

\section{Introduction}

Polycyclic aromatic hydrocarbons (PAHs) are hydrophobic organic compounds containing two or more benzene rings [1]. Also, PAHs have toxic, mutagenic and carcinogenic effects, high volatility, easily transportable in the atmosphere and photo-degradable compounds that can react with nitrogen oxides $\left(\mathrm{NO}_{\mathrm{x}}\right)$ and ozone $\left(\mathrm{O}_{3}\right)$ [2]. These compounds are usually released during the incomplete combustion of organic materials such as wood, coal, and oil [3]. PAHs are common in the atmosphere and the first pollutants known as possible carcinogens [4]. Some PAH compounds have been listed as priority pollutants by the US Environmental Protection Agency (USEPA) because of their toxic and mutagenic effects [5]. The International Agency for Research on Cancer (IARC) has classified some types of PAH as probable or possibly carcinogenic to humans (Group 1, 2A or 2B). IARC has categorised the compounds in Group 1 as "carcinogens for humans," the compounds in Group 2 as "possible carcinogens for humans," the compounds in Group 2B as "probable carcinogens for humans," and finally the Group 3 as "non-carcinogenic compounds for humans" [6].

Currently, both active and passive sampling methods are widely used to determine the concentration values of semivolatile organic compounds (SVOCs), such as PAHs [7]. Active air sampling systems have several disadvantages such as high equipment costs, the need for a power supply and maintenance by qualified personnel $[8,10]$. Therefore, passive air samplers (PASs) have become a suitable alternative for active air samplers (AASs), which are a generic method for monitoring SVOCs [11]. PASs were first used in the late 1920s, but they could not be transformed into a quantitative methodology until the 1970s [12]. Fick's diffusion law was first applied in 1973 in the development of passive sampling techniques, and these systems were rapidly developed and widely used to monitor pollutants in different environments [13]. 
10 000-25 000 honey bees come out from the hive about 10 times to collect nectar, water, and pollen from flowers in an area of $7 \mathrm{~km}^{2}$ every day [14]. A single bee exiting from a hive circulates 80-100 flowers per day [15], during this activity various microorganisms, chemicals, and particles are kept in the body of bees [14]. For this reason, honey bees are used to monitor the distribution and effects of various hazardous chemicals, heavy metals, radionuclides, pesticides and including organic pollutants such as PAHs [3].

In this study, PAH species measured in honey bee media and passive air sampler in ambient air from urban and semi-urban sites were analysed to i) compare the monthly concentration levels; ii) determine the differences between sites; and iii) calculate the cancer risk caused by inhalation.

\section{Materials and methods}

\subsection{Sampling sites and sample collection}

The study was carried out in the apiaries of the Ovaakca and Cumalikizik sites in Bursa. The apiary area in Cumalikizik is located in the east of the city, in an open area, close to the chestnut and pine forests. It is located 360 meters above sea level, $3 \mathrm{~km}$ away from the settlements and $5 \mathrm{~km}$ away from the nearest highway. The Ovaakca site is situated on the Bursa-Yalova road in the north of the city, $3 \mathrm{~km}$ from the Demirtas Organized Industrial Zone (DOSAB) and $1.5 \mathrm{~km}$ from the Bursa-Ankara highway. The apiary of the area is located on the ridges of the natural pine forest. The sampling sites are shown in Figure 1.

Honeybees (Apis mellifera) and PUF-PAS samples were collected in 2017 during the beekeeping period (May to end of September). Samples were taken every 15 days from each site. Passive air sampler is a device that allows PAH compounds to pass at a constant and known speed through a polyurethane foam (PUF) disc [16]. The PAS was located approximately 2-3 $\mathrm{m}$ above the ground in the sampling sites. The PUF discs were wrapped in aluminium foil and transported in a lid glass jar. The samples of foraging honeybees bees collected from the entrance of each beehive were put into a glass jar. The collected samples were immediately placed inside of a plastic insulated container after sampling and stored in a standard freezer at $-20{ }^{\circ} \mathrm{C}$ until analysis.
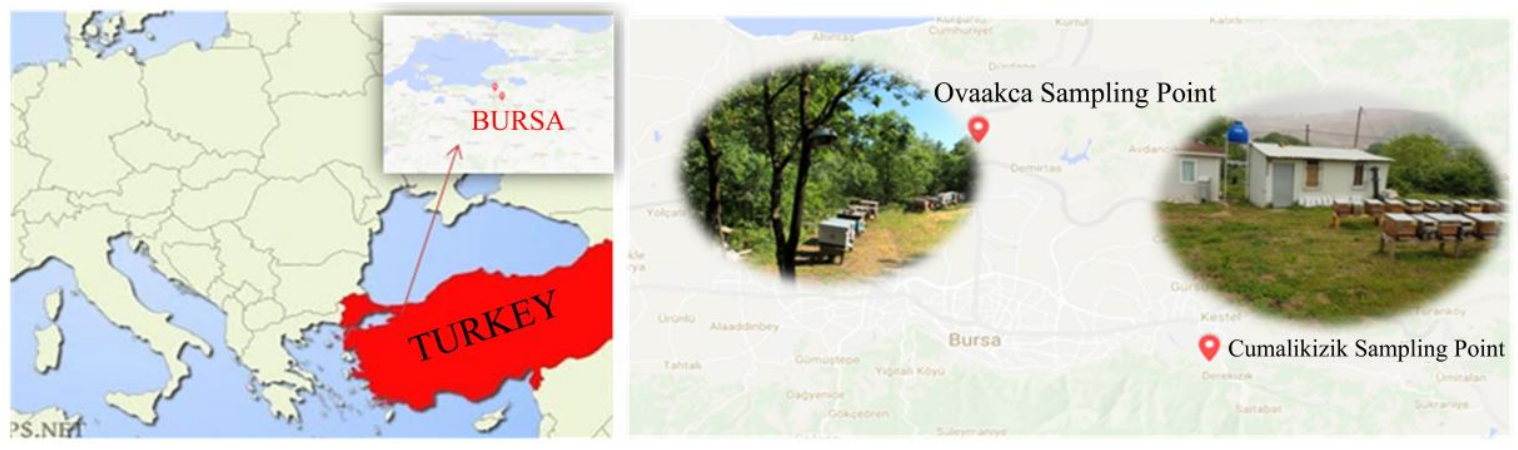

Fig. 1: Sampling sites.

\subsection{Sample Preparation and Analysis}

Before extraction, PAH standards (naphthalene-d8, acenaphthene-d10, phenanthrene-d10, chrysene-d12, and perylene-d12) were added to honeybee and PUF disc samples to determine recoveries during the tests. The PUF disks were exposed to the Soxhlet extraction for $24 \mathrm{~h}$ using approx $250 \mathrm{~mL}$ of acetone: hexane mixture (ACE/HEX, 1:1 v/v).

$2 \mathrm{~g}$ of the bee samples were taken into the bottle and crushed. $50 \mathrm{~mL}$ of dichloromethane / petroleum ether (DCM/PE, 1: 1) was added to the bottle and stirred on a shaker (Multi Shaker FMS3 FINEPCR, Korea) for 2 hours. The samples were then extracted for 15 minutes using an ultrasonic bath (Elmasonic S $80 \mathrm{H}$ Model, Germany) and the solvent was taken into a separate flask. Afterwards, $40 \mathrm{~mL}$ of ACE / HEX (1:1) mixture was added to the sample bottle and extracted for 30 minutes in an ultrasonic bath. Extracts were combined at the end of the process [17].

The volumes of the PUF and bee samples, whose extraction was completed, were reduced to $2 \mathrm{~mL}$ with a rotary evaporator (Laborota 4001-Heidolph, Germany) at a speed of about $30 \mathrm{rpm}$ [18]. The bee samples were then passed through the gel permeation chromatography column (GPC) for final cleaning [19]. The volume of the bee samples was again reduced and then and stored in a freezer at $-20^{\circ} \mathrm{C}$ until fractionation. Sodium sulfate $\left(\mathrm{Na}_{2} \mathrm{SO}_{4}-\mathrm{Merck}\right)$ and aluminium oxide $\left(\mathrm{Al}_{2} \mathrm{O}_{3}\right.$-Merck) to be used in the fraction process were activated by storing them in the muffle furnace 
at $450{ }^{\circ} \mathrm{C}$ for $4 \mathrm{~h}$. Silicic acid $\left(\mathrm{H}_{4} \mathrm{SiO}_{4}\right.$-Sigma Aldrich) was activated by storing it in the oven at $105{ }^{\circ} \mathrm{C}$ for 1 day. Then, the samples were passed through a clean-up column containing $1 \mathrm{~cm}$ (about $2 \mathrm{~g}$ ) sodium sulfate $\left(\mathrm{Na}_{2} \mathrm{SO}_{4}\right), 2 \mathrm{~g}$ of aluminium oxide (6\% pure water) and $3 \mathrm{~g}$ of silicic acid (3\% pure water). The column was cleaned with $20 \mathrm{~mL}$ DCM and then with 20 $\mathrm{mL}$ PE. After this step, $2 \mathrm{~mL}$ of sample was poured into the column. To collect the fraction containing the PAHs, $20 \mathrm{~mL}$ of DCM was then added. The solvent was exchanged into HEX, and final sample volume was adjusted to $1 \mathrm{~mL}$ using rotary evaporator. All samples were prepared for measurement at gas chromatography-mass spectrometry $(\mathrm{GC}-\mathrm{MS})[18,20]$.

\subsection{Instrumental Analysis}

Analysis of samples and blanks were performed using the Agilent 7890A GC and Agilent 5975C inert XL triaxial mass detector. A capillary column (HP5-MS, $30 \mathrm{~m} \times 0.32 \mathrm{~mm} \times 0.25 \mu \mathrm{m}$ ) was used in GC-MS. The injector, ion source and quadrupole temperatures were 295,300 and $180^{\circ} \mathrm{C}$, respectively. The oven temperature program used in the PAH analyses was as follows: increase to $50{ }^{\circ} \mathrm{C}(1 \mathrm{~min})$, increase to $200{ }^{\circ} \mathrm{C}$ at $25^{\circ} \mathrm{C} / \mathrm{min}$, increase from 200 to $300{ }^{\circ} \mathrm{C}$ at $8{ }^{\circ} \mathrm{C} / \mathrm{min}$, wait 5.5 min at $300{ }^{\circ} \mathrm{C}$, increase to $310{ }^{\circ} \mathrm{C}$ at $5{ }^{\circ} \mathrm{C} / \mathrm{min}$ and wait $3 \mathrm{~min}$. As the carrier gas was helium $(\mathrm{He})$ at $1.2 \mathrm{~mL} / \mathrm{min} \mathrm{constant}$ flow rate. MS was performed in ion- monitoring mode (SIM) which was selected for high precision. Determination of PAH types was performed based on the retention times and target ion peaks.

In this study, priority $16 \mathrm{PAH}$ species including naphthalene (Nap), acenaphthylene (Acy), acenaphthene (Ace), fluorene (Fln), phenanthrene (Phe), anthracene (Ant), fluoranthene $(\mathrm{Fl})$, pyrene $(\mathrm{Py})$, benz(a)anthracene $(\mathrm{BaA})$, chrysene $(\mathrm{Chr})$, benzo(b)fluoranthene $(\mathrm{BbF})$, benzo(k)fluoranthene $(\mathrm{BkF})$, benzo(a)pyrene $(\mathrm{BaP})$, indeno(1,2,3-c,d)pyrene (IcdP), dibenz(a,h)anthracene (DahA), and benzo(g,h,i)perylene (BghiP) were analyzed. In the study 14 and 13 PAH species were determined in the PUF-PAS and bee samples, respectively.

\subsection{Quality assurance/quality control (QA/QC)}

All samples and blanks were spiked with surrogate standards $(1 \mathrm{~mL})$, before extraction, to determine analytical recovery efficiencies. More than $10 \%$ of the total samples were taken as blank samples, and it was determined whether there was any contamination during the sampling/analyses. The limit of detection (LOD) values were calculated by adding three times the standard deviation to the average PAH concentrations in the blank samples. PAHs with values less than the determined LOD values were ignored and were not included in the calculations. Air passing through PAS was taken as $3.5 \mathrm{~m}^{3} / \mathrm{day}$ [21].

Before the PAH analysis, a calibration curve was drawn according to the five concentration values $(0.20,0.40,0.64$, 1.0 and $5.0 \mu \mathrm{g} / \mathrm{mL}$ ) to define the linearity of the results of the GC-MS device. The $\mathrm{r}^{2}$ value of the calibration curve was 0.99 . The performance of the device was checked by analysing a midpoint calibration standard in every 24 samples.

\subsection{Statistical analysis}

Sigmaplot ${ }^{\circledR} 13.0$ statistical program was used for the regression parameters and graphs.

\section{Results and discussion}

\subsection{PAH concentrations in PUF-PAS and bee samples}

The samples were collected in the 15-day period (from May to the end of September) during the 2017 beekeeping period. In this study, the mean $\sum_{14} \mathrm{PAH}$ concentration obtained by PAS was found to be $198.62 \pm 24.93 \mathrm{ng} \mathrm{m}^{-3}$ in Ovaakca site, and $445.47 \pm 59.21 \mathrm{ng} \mathrm{m}^{-3}$ in Cumalikizik site. The mean $\sum_{13} \mathrm{PAH}$ concentration of bee samples was $380.87 \pm 115.33 \mathrm{ng} \mathrm{g} \mathrm{gw}^{-1} \mathrm{dw}$ and $217.96 \pm 30.10 \mathrm{ng} \mathrm{g}^{-1} \mathrm{dw}$ for Ovaakca and Cumalikizik sites, respectively. Figure 2 shows the change in PAH concentrations of PUF discs and bee samples according to months and site. 

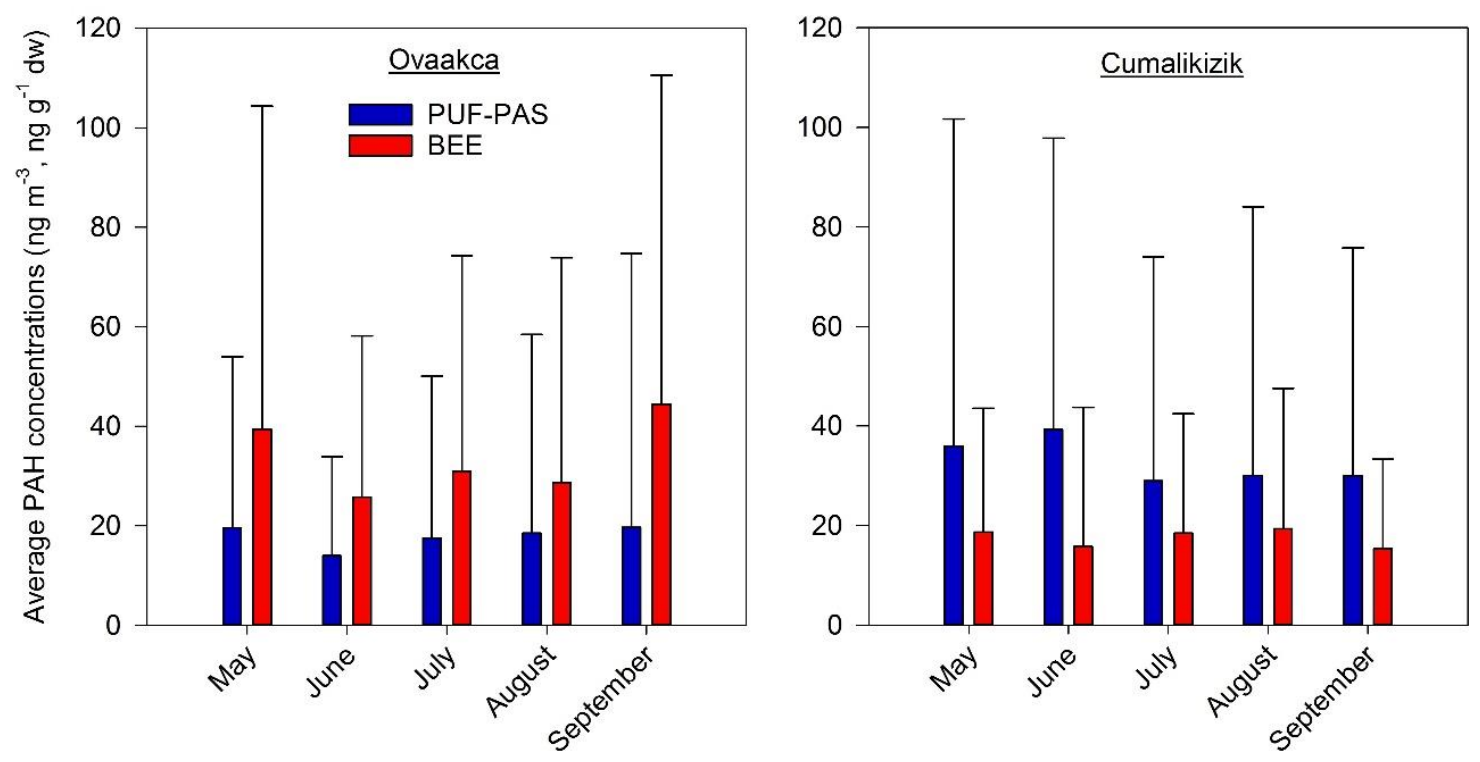

Fig. 2: Monthly distribution of PAH concentrations in PUF-PAS and bee samples.

In the Ovaakca site, the amount of PAHs in the bee samples was higher compared to the PUF-PAS, it was lower in the Cumalikizik site, yet. In the bee samples, the highest concentration of PAHs was determined in the Ovaakca site in September while the lowest concentration was determined in the Cumalikizik site in September. Also, in PUF PAS, the lowest PAH concentration was determined in Ovaakca site in June, and the highest concentration was measured in Cumalikizik site in the same month.

Honeybees are often exposed to the action of pollutants present in the surroundings of the hives from spring to autumn, an area that may be as large as $5-7 \mathrm{~km}^{2}$. When foraging, the bees carry back to the hive the contaminants contained in their feed, as well as those deposited on the surfaces of the flowers and leaves of the plants that they visited $[3,22,23]$. Therefore, high concentrations of PAHs in bee samples are expected. Although the apiary in Ovaakca site was close to settlement, highway and main roads, it was located in a wooded area surrounded by pine trees. The impact of vegetation on the life and transport cycles of different organic pollutants are considered very important and a "forest filter effect'" was already declared. In other words, atmospheric PAH concentrations decrease in forest areas [24, 25]. In the literature, pine trees were also used in the monitoring of persistent organic pollutants (POPs), and they showed good yields in the removal of PAHs from the air [24, 26, 27]. The fact that POPs are also determined in pine trees suggests that some pollution is passed to the passive air sampler. Therefore, in the Ovaakca site, PUF-PAS samples had low PAHs, but high concentrations could be seen in bee samples due to their long-distance travel and location of the site.

In contrast to the Ovaakca site, in the Cumalikizik site, which had lower vehicle traffic, close to settlement and picnic areas, the PAH concentration in PUF-PAS samples was higher than the samples of bees. The distribution of PUFPAS and bee samples by sites and PAH species is given in Figure 3. 


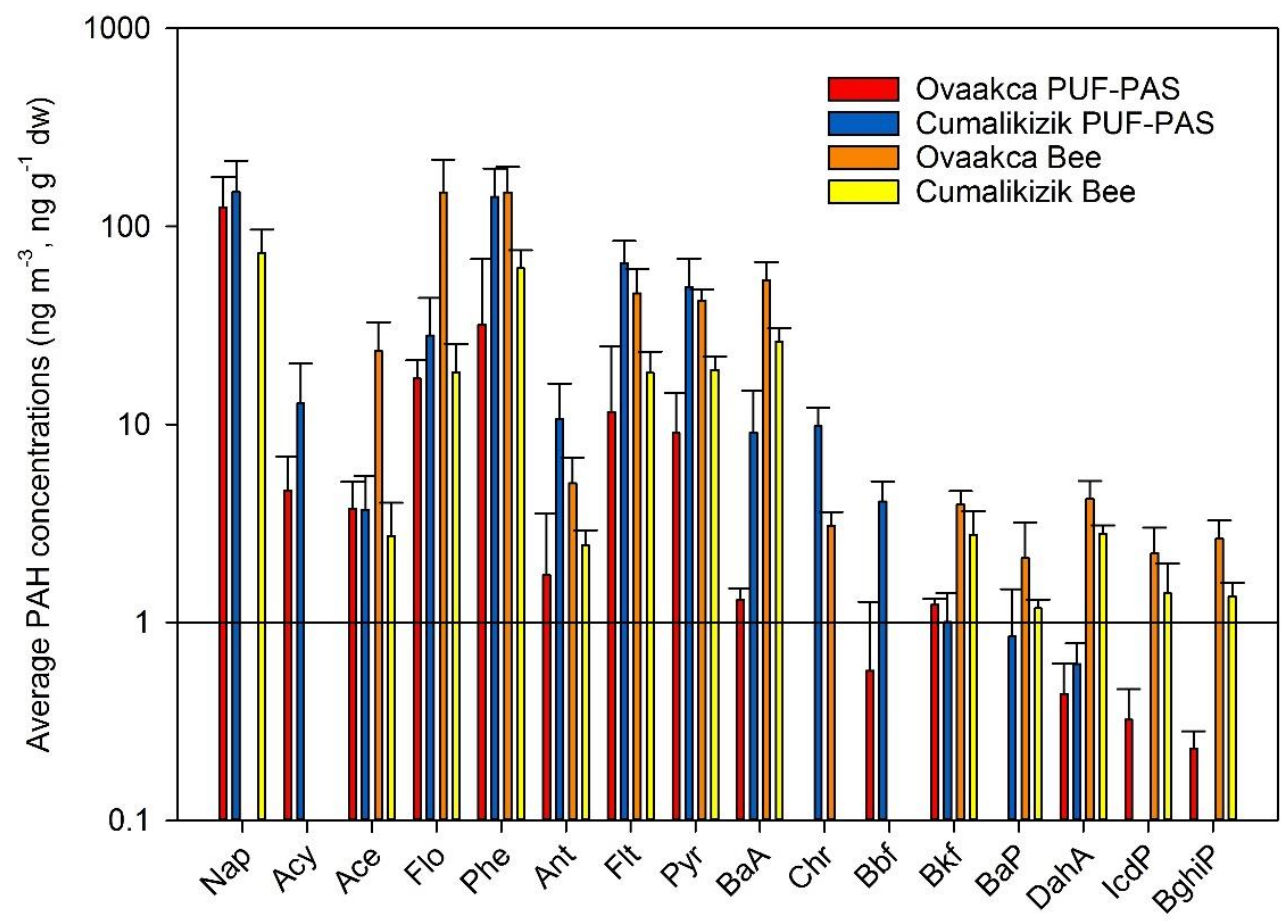

Fig. 3: PAH species distributions in the sampling sites.

Nap, was dominant for PUF-PAS samples in both sites. Also, Phe was the second dominant species in the Cumalikizik region. In the bee samples, Flo and Phe were the dominant species in the Ovaakca site, while Nap and Phe were the dominant species in the Cumalikizik site. Also, PUF-PAS and bee samples were dominated by 2 and 3-ring PAHs in both places. The ratio of high molecular weight (5 - 6 ring) PAHs was also very low.

Variance analysis (ANOVA) was performed to determine whether the concentrations of PAHs showed a significant difference between sites. The difference between the median values between the two sites of the PUF-PAS and bee samples were found to be higher than expected by chance. Therefore, there was a statistically significant difference $(p=0.008$ (PUFPAS), 0.002 (bee) <0.05).

\subsection{Determination of cancer risk in PAHs}

PAHs are chemical compounds produced by incomplete combustion of carbonaceous compounds. Many types of PAHs present in the outdoor air have mutagenic and/or carcinogenic effects [28]. Exposure to inhalation dose is a function of the inhalation rate with the concentration of the pollutants and is calculated by Equation 1 [29].

$$
\text { Dose }=\frac{\left(C_{a} \times(D B R) \times A \times E F \times E D \times 10^{-9}\right)}{A T}
$$

Where, Dose is the exposure to inhalation dose $\left(\mathrm{mg} \mathrm{kg}^{-1}\right.$ day $\left.^{-1}\right), \mathrm{C}_{\mathrm{a}}$ is the specific PAH compound concentrations measured with the PAS $\left(\mathrm{ng} \mathrm{m}{ }^{-3}\right)$, DBR is the daily breathing rate $\left(\mathrm{L} \mathrm{kg}^{-1}\right.$ (body weight) day $\left.{ }^{-1}\right), \mathrm{A}$ is the respiratory absorption factor, EF is the frequency of exposure (day year ${ }^{-1}$ ), ED is exposure time (year), AT is the mean time of exposure. In this study, DBR was assumed to be 271 for adults (70 years), A was assumed to be 1 for adults; EF was assumed to be 350 days year $^{-1}$, ED was assumed to be 70 years for adults, AT was assumed to be 25550 for adults [29]. The dose values calculated in urban and semi-urban areas for adults are given in Table 1. 
Table 1: Calculated dose values in urban and semi-urban areas.

\begin{tabular}{|c|c|c|c|c|c|c|c|c|c|c|}
\hline & \multicolumn{10}{|c|}{$\operatorname{DOSE}\left(\times 10^{-6}\right)\left(\mathrm{mg} \mathrm{kg}^{-1} \mathrm{day}^{-1}\right)$} \\
\hline & \multicolumn{5}{|c|}{ Ovaakca (Urban Area) } & \multicolumn{5}{|c|}{ Cumalikizik (Semi-Urban Area) } \\
\hline Compound & May & June & July & August & Sep. & May & June & July & August & Sep. \\
\hline $\mathrm{BaP}$ & N.D & N.D & N.D & N.D & N.D & 0.17 & 0.16 & 0.12 & 0.51 & 0.15 \\
\hline $\mathrm{BaA}$ & N.D & N.D & 0.37 & 0.30 & N.D & 2.68 & 1.93 & 1.14 & 4.82 & 1.29 \\
\hline $\mathrm{BbF}$ & 0.51 & 0.16 & N.D & 0.13 & 0.16 & 1.53 & 1.09 & 0.90 & 0.88 & 0.90 \\
\hline $\mathrm{BkF}$ & 0.29 & N.D & N.D & N.D & 0.32 & 0.27 & 0.25 & 0.17 & 0.43 & 0.19 \\
\hline Chr & N.D & N.D & N.D & N.D & N.D & 3.59 & 2.65 & 2.30 & 2.15 & 2.05 \\
\hline
\end{tabular}

N.D: No Data

The risk of cancer was determined by multiplying the dose of exposure by inhalation, and the potential factor of cancer is given in Table $2[29,30]$.

Table 2: Potential factor in cancer through inhalation.

\begin{tabular}{|c|c|}
\hline Compound & Potential factor in cancer through inhalation $\left(\mathrm{mg} \mathrm{kg}^{-1} \mathrm{day}^{-1}\right)^{-1}$ \\
\hline $\mathrm{BaP}$ & 3.9 \\
\hline $\mathrm{BaA}$ & 0.39 \\
\hline $\mathrm{BbF}$ & 0.39 \\
\hline $\mathrm{BkF}$ & 0.39 \\
\hline $\mathrm{Chr}$ & 0.039 \\
\hline
\end{tabular}

It is necessary to multiply $10^{6}$ by calculating the probability of the estimated cancer risk in a million cancer. The risk of million ${ }^{-1}$ cancer found is given in Table 3 .

Table 3: The risk of cancer (1/million).

\begin{tabular}{|c|c|c|c|c|c|c|c|c|c|c|}
\hline & \multicolumn{5}{|c|}{ Ovaakca (Urban Area) } & \multicolumn{4}{c|}{ Cumalikizik (Semi-Urban Area) } \\
\hline Compound & May & June & July & August & Sep. & May & June & July & August & Sep. \\
\hline BaP & N.D & N.D & N.D & N.D & N.D & 0.67 & 0.64 & 0.45 & $\mathbf{1 . 9 8}$ & 0.57 \\
\hline BaA & N.D & N.D & 0.15 & 0.12 & 0.00 & $\mathbf{1 . 0 5}$ & 0.75 & 0.45 & $\mathbf{1 . 8 8}$ & 0.50 \\
\hline BbF & 0.20 & 0.06 & N.D & 0.05 & 0.06 & 0.60 & 0.43 & 0.35 & 0.34 & 0.35 \\
\hline BkF & 0.11 & N.D & N.D & N.D & 0.12 & 0.11 & 0.10 & 0.06 & 0.17 & 0.07 \\
\hline Chr & N.D & N.D & N.D & N.D & N.D & 0.14 & 0.10 & 0.09 & 0.08 & 0.08 \\
\hline Total & 0.31 & 0.06 & 0.15 & 0.17 & 0.18 & 2.56 & 2.02 & 1.40 & $\mathbf{4 . 4 6}$ & 1.57 \\
\hline
\end{tabular}

ND: No Data

According to Table 3, total cancer risk values were below the acceptable risk level $\left(1 \times 10^{-6}\right)$ in Ovaakca region, while it was found high during all sampling periods at Cumalıkızı region. The highest total cancer risk was determined in August and, $\mathrm{BaP}$ with $\mathrm{BaA}$ played an important contribution to the cancer risk. BaA characterizes oil production [31], diesel and biodiesel emissions, while BaP describes emissions from wood burning [32]. In Cumalikizik, which represents the semi-urban site, it is common to have diesel and biodiesel emissions in this site since agricultural activities are high. Furthermore, it is explained by the evaporation of more PAH compounds and/or high concentrations of PAH compounds in the gas phase in the warmer months like August [33]. Also, the Cumalikizik sampling site has a picnic 
area where there is plenty of barbecuing, unlike the Ovaakca site. Especially in the hot months like July and August, picnic activities were quite high, and therefore the PAH concentrations were high in the Cumalikizik sampling site. It is thought that the Ovaakca sampling site was not affected by human activities because it was located inside the pine trees.

\section{Conclusion}

The PUF-PAS and bee samples were taken in urban and semi-urban sites in Bursa, Turkey and PAH concentrations were measured. Honeybees and PASs exhibited good capacity in the determination of POPs. PAH concentrations were higher in PUF-PAS samples at the Cumalikizik site. PAH levels were measured less in the PUF-PAS samples due to the forest effect and the surrounding of the Ovaakca site. It was observed that bees were exposed to all pollutants because of their large activity areas. Due to its proximity to main roads and industrial zone (DOSAB), high PAH levels were determined in bee samples in the Ovaakca site. Low molecular weight PAHs (2-3 rings) were dominant in all samples for both sites. There was a statistically significant difference in both samples. The highest cancer risk was determined in August with $\mathrm{BaP}$ and $\mathrm{BaA}$ at the Cumalikizik site. The high amount of PAHs in the semi-urban site with high agricultural activities increased the risk of cancer-related to these PAH species.

\section{Acknowledgements}

This work was supported by The Scientific and Technologic Research Council of Turkey (Project number: 116Y208).

\section{References}

[1] A. Paris, J. Ledauphin, P. Poinot and J. L. Gaillard, "Polycyclic aromatic hydrocarbons in fruits and vegetables: Origin, analysis, and occurrence," Environ. Pollut., vol. 234, pp. 96-106, 2018.

[2] A. M. Mastral, M. S. Callén, J. M. López, R. Murillo, T. García and M. V. Navarro, "Critical review on atmospheric PAH. Assessment of reported data in the Mediterranean basin," Fuel Process. Technol., vol. 80, no. 2, pp. 183-193, 2003.

[3] N. Kargar, G. Matin, A. A. Matin and H. B. Buyukisik, "Biomonitoring, status and source risk assessment of polycyclic aromatic hydrocarbons (PAHs) using honeybees, pine tree leaves, and propolis," Chemosphere, vol. 186, pp. 140-150, 2017.

[4] K. H. Kim, S. A. Jahan, E. Kabir and R. J. C. Brown, "A review of airborne polycyclic aromatic hydrocarbons (PAHs) and their human health effects," Environ. Int., vol. 60, pp. 71-80, 2013.

[5] A. D. Zand and P. Grathwohl, "Enhanced immobilization of polycyclic aromatic hydrocarbons in contaminated soil using forest wood-derived biochar and activated carbon under saturated conditions, and the importance of biochar particle size," Polish J. Environ. Stud., vol. 25, no. 1, pp. 427-441, 2016.

[6] S. Santonicola, S. Albrizio, N. Murru, M. C. Ferrante and R. Mercogliano, "Study on the occurrence of polycyclic aromatic hydrocarbons in milk and meat/fish based baby food available in Italy," Chemosphere, vol. 184, pp. 467-472, 2017.

[7] R. Magnusson, K. Arnoldsson, C. Lejon, L. Hägglund and H. Wingfors, "Field evaluation and calibration of a small axial passive air sampler for gaseous and particle bound polycyclic aromatic hydrocarbons (PAHs) and oxygenated PAHs," Environ. Pollut., vol. 216, pp. 235-244, 2016.

[8] M. Mari, M. Schuhmacher, J. Feliubadaló and J. L. Domingo, "Air concentrations of PCDD/Fs, PCBs and PCNs using active and passive air samplers," Chemosphere, vol. 70, no. 9, pp. 1637-1643, 2008.

[9] L. Tuduri, M. Millet, O. Briand and M. Montury, "Passive air sampling of semi-volatile organic compounds," $\operatorname{TrAC}$ Trends Anal. Chem., vol. 31, no. 2, pp. 38-49, 2012.

[10] Q. Xu et al., "Simultaneous monitoring of PCB profiles in the urban air of Dalian, China with active and passive samplings," J. Environ. Sci. (China), vol. 25, no. 1, pp. 133-143, 2013.

[11] N. Domínguez-Morueco, M. Schuhmacher, J. Sierra, M. Nadal and J. L. Domingo, “Assessment of PAH loss in passive air samplers by the effect of temperature," Atmos. Pollut. Res., vol. 7, no. 1, pp. 142-146, 2016.

[12] K. M. Ellickson et al., "Analysis of polycyclic aromatic hydrocarbons (PAHs) in air using passive sampling calibrated with active measurements," Environ. Pollut., vol. 231, pp. 487-496, 2017.

[13] T. D. Ramos, M. de la Guardia, A. Pastor and F. A. Esteve-Turrillas, "Assessment of air passive sampling uptakes for volatile organic compounds using VERAM devices,” Sci. Total Environ., vol. 619-620, pp. 1014-1021, 2018.

[14] S. R. Rissato, M. S. Galhiane, M. V. de Almeida, M. Gerenutti and B. M. Apon, "Multiresidue determination of 
pesticides in honey samples by gas chromatography-mass spectrometry and application in environmental contamination," Food Chem., vol. 101, no. 4, pp. 1719-1726, 2007.

[15] C. Nisbet, A. Guler, G. F. Yarim, S. Cenesiz and Y. Ardali, "Relationship between environmental and flora change with mineral content of honey bee products," Turkish J. Biochem., vol. 38, no. 4, pp. 494-498, 2013.

[16] US EPA, "Passive Samplers for Investigations of Air Quality: Method Description, Implementation, and Comparison to Alternative Sampling Methods," United States Environ. Prot. Agency, no. Engineering Issue, pp. 1-22, 2015.

[17] A. Birgül, Y. Tasdemir and S. S. Cindoruk, "Atmospheric wet and dry deposition of polycyclic aromatic hydrocarbons (PAHs) determined using a modified sampler," Atmos. Res., vol. 101, no. 1-2, pp. 341-353, 2011.

[18] F. Esen, S. S. Cindoruk and Y. Tasdemir, "Ambient Concentrations and Gas/Particle Partitioning of Polycyclic Aromatic Hydrocarbons in an Urban Site in Turkey," Environ. Forensics, vol. 7, no. 4, pp. 303-312, 2006.

[19] W. A. Ockenden, E. Steinnes, C. Parker and K. C. Jones, "Observations on Persistent Organic Pollutants in Plants: Implications for Their Use as Passive Air Samplers and for POP Cycling," Environ. Sci. Technol., vol. 32, no. 18, pp. 2721-2726, 1998.

[20] S. Siddik Cindoruk and Y. Tasdemir, "Characterization of gas/particle concentrations and partitioning of polychlorinated biphenyls (PCBs) measured in an urban site of Turkey," Environ. Pollut., vol. 148, no. 1, pp. 325-333, 2007.

[21] C. Chaemfa, J. L. Barber, K. S. Kim, T. Harner and K. C. Jones, "Further studies on the uptake of persistent organic pollutants (POPs) by polyurethane foam disk passive air samplers," Atmos. Environ., vol. 43, no. 25, pp. 3843-3849, 2009.

[22] A. Ciemniak, A. Witczak and K. Mocek, "Assessment of honey contamination with polycyclic aromatic hydrocarbons," J. Environ. Sci. Heal. - Part B Pestic. Food Contam. Agric. Wastes, vol. 48, no. 11, pp. 993-998, 2013.

[23] Z. Bargańska, M. Tebioda and J. Namies̈nik, "Honey bees and their products: Bioindicators of environmental contamination," Crit. Rev. Environ. Sci. Technol., vol. 46, no. 3, pp. 235-248, 2016.

[24] N. Ratola, J. M. Amigo and A. Alves, "Comprehensive assessment of pine needles as bioindicators of PAHs using multivariate analysis. The importance of temporal trends," Chemosphere, vol. 81, no. 11, pp. 1517-1525, 2010.

[25] J. H. Syed et al., "Polycyclic aromatic hydrocarbons (PAHs) in Chinese forest soils: Profile composition, spatial variations and source apportionment," Sci. Rep., vol. 7, no. 1, pp. 1-10, 2017.

[26] E. Holt, A. Kočan, J. Klánová, A. Assefa and K. Wiberg, "Polychlorinated dibenzo-p-dioxins/furans (PCDD/Fs) and metals in scots pine (Pinus sylvestris) needles from Eastern and Northern Europe: Spatiotemporal patterns, and potential sources," Chemosphere, vol. 156, pp. 30-36, 2016.

[27] F. De Nicola et al., "Evergreen or deciduous trees for capturing PAHs from ambient air? A case study," Environ. Pollut., vol. 221, pp. 276-284, 2017.

[28] M. Lodovici, M. Venturini, E. Marini, D. Grechi, and P. Dolara, "Polycyclic aromatic hydrocarbons air levels in Florence, Italy, and their correlation with other air pollutants," Chemosphere, vol. 50, no. 3, pp. 377-382, 2003.

[29] A. Hanedar, "Determination and evaluation of atmospheric concentration and deposition of polycyclic aromatic hydrocarbons in Istanbul," Ph.D. Thesis, Istanbul Technical University, Department of Environmental Engineering, pp. 268, 2009.

[30] W. Yang, Y. H. Lang, J. Bai and Z. Y. Li, "Quantitative evaluation of carcinogenic and non-carcinogenic potential for PAHs in coastal wetland soils of China," Ecol. Eng., vol. 74, pp. 117-124, 2015.

[31] N. D. Dat and M. B. Chang, "Review on characteristics of PAHs in atmosphere, anthropogenic sources and control technologies," Sci. Total Environ., vol. 609, pp. 682-693, 2017.

[32] S. Taghvaee, M. H. Sowlat, M. S. Hassanvand, M. Yunesian, K. Naddafi and C. Sioutas, "Source-specific lung cancer risk assessment of ambient PM2.5-bound polycyclic aromatic hydrocarbons (PAHs) in central Tehran," Environ. Int., vol. 120, no. April, pp. 321-332, 2018.

[33] G. Liu, G. Zhang, J. Li, X. Li, X. Peng and S. Qi, "Spatial distribution and seasonal variations of polycyclic aromatic hydrocarbons (PAHs) using semi-permeable membrane devices (SPMD) and pine needles in the Pearl River Delta, South China," Atmos. Environ., vol. 40, no. 17, pp. 3134-3143, 2006. 